\title{
Facultad de Estomatología de la Universidad Peruana Cayetano Heredia: Verdadera institución líder en la Odontología Peruana
}

School of Dentistry Peruvian University Cayetano Heredia: True leading institution in Peruvian Dentistry.

1. Valores éticos y morales

2. Honestidad.

3. Responsabilidad.

4. Conductor a través del ejemplo

5. Superación constante

6. Hace de su vida una visión, no una característica.

7. Introduce nuevas ideas.

8. No temer al cambio.

9. Capacidad de trabajar en equipo.

10. Pensamiento estratégico y a futuro.

11. Obtiene el respaldo de los demás.

Al ver todas estas características y realizando una analogía podemos identificar a la Facultad de Estomatología de la Universidad Peruana Cayetano Heredia ( FAEST-UPCH ) como una VERDADERA institución líder en la Odontología Peruana.

Es que en la FAEST-UPCH podemos identificar las siguientes características de liderazgo:

1. Valores éticos y morales. Podemos identificar los valores heredianos (excelencia, honestidad, transparencia, respeto, compromiso, responsabilidad).

2. Honestidad. Es uno de los valores heredianos.

3. Responsabilidad. Es uno de los valores heredianos.

4. Por 50 años la FAEST-UPCH ha predicado con en el ejemplo.

5. Ha obtenido a nivel internacional la acreditación y reacreditación con la CNA de Colombia y a nivel nacional con el SINEACE. Asimismo tiene el ISO 9001 - 2015.

6. La FAEST-UPCH introdujo en el Perú, un modelo educativo innovador de enseñanza - aprendizaje en odontología. 
7. Lo único constante es el cambio.

8. La visión de la FAEST-UPCH es liderazgo y presencia internacional, con crecimiento, innovación e investigación, con cultura de calidad, promoviendo políticas de salud pública.

9. La FAEST-UPCH introduce el equipo humano en odontología integrado por el estomatólogo, la asistenta dental y el técnico de laboratorio.

10. A través de los años se establece su propio plan estratégico.

11. Ha recibido a lo largo de sus 50 años el respeto de la comunidad odontológica.

Por todo lo expuesto, podemos concluir que la FAEST-UPCH es sin lugar a dudas la institución líder en la Odontología Peruana.

\section{Mg. Hugo Ronquillo-Herrera ${ }^{1, a . b, c ; ~ 2, d}$}

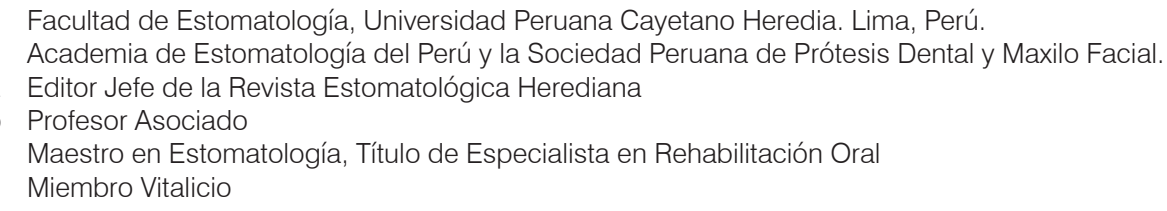

